\title{
Hydrometeorological Triggering of Periglacial Debris Flows Using a Bayesian Approach: A Case Study of the Hailuogou Gully Region, China
}

\author{
Zheng Wang \\ Institute of Mountain Hazards and Environment Chinese Academy of Sciences \\ Ningsheng Chen ( $\nabla$ chennsh@imde.ac.cn) \\ Institute of Mountain Hazards and Environment https://orcid.org/0000-0002-6135-0739 \\ Guisheng Hu \\ Institute of Mountain Hazards and Environment Chinese Academy of Sciences \\ Yong Zhang \\ Institute of Mountain Hazards and Environment Chinese Academy of Sciences \\ Genxu Wang \\ Institute of Mountain Hazards and Environment Chinese Academy of Sciences \\ Zheng Han \\ Central South University
}

\section{Research Article}

Keywords: periglacial debris flows, meteorological causes, extreme climate, Bayesian probability, early warning threshold

Posted Date: July 12th, 2021

DOI: https://doi.org/10.21203/rs.3.rs-673988/v1

License: (c) (i) This work is licensed under a Creative Commons Attribution 4.0 International License. Read Full License 


\section{Abstract}

Mount Gonggais located in the east of the Qinghai-Tibet Plateau; many debris flows have occurred in small basins with a small glacier cover or snow cover in this area. The hydrometeorological conditions that caused debris flows in this region are complex, making forecasting and early warning difficult. Previous studies for these small-glacial-covered basins have primarily considered rainfall as the only inducing factor of debris flows, and often the effects of temperature are neglected. Thus, we carried out a probabilistic analysis of variables derived from hydrometeorological factors for the Mount Gongga region, Sichuan, China, where debris flows were recorded on 14 days between 1988 and 2019. By analyzing hydrological characteristics when debris flows occurred, three distinct dominant trigger types could be identified. The results show that 7 (50\%) of the observed debris flow events during the study period, highintensity rainfall was the dominant trigger, snowmelt by high temperature was identified as the dominant trigger for 2 ( $14 \%$ ). Furthermore, 5 ( $36 \%$ ) debris flow events could be attributed to the combined effects of long-lasting (or short-medium) rainfall and sustained higher temperatures. We find that the differences between the trigger types are statistically significant, and a susceptibility prediction differentiating between trigger types can outperform simple rainfall-only situations. This study contributes to an improved understanding of the hydrometeorological impact on debris flow initiation in high elevation watersheds.

\section{Introduction}

Debris flows containing large quantities of particles are common phenomena observed in mountainous areas worldwide (Pavlova et al., 2011). It is known that short-term rainfall with a high intensity can trigger debris flows (Berti et al., 1999; Caine, 1980; Wilson and Wieczorek, 1995). Many studies have analyzed thresholds (antecedent rainfall), rainfall intensity, and duration as triggering factors to understand debris flow initiation (Caine, 1980; Glade et al., 2000; Guzzetti et al., 2007; Guzzetti et al., 2008; Osanai et al., 2010). Periglacial debris flows form in glacier and snow-covered areas at a distance from the front of the glacier or near the snow line. The occurrence of debris flows in such regions is triggered by long-term continuous rainfall and short-term heavy rainfall (Chiarle et al., 2007), ice and snow melting (Decaulne et al., 2005; Matsuura et al., 2013), and snow melting and rainfall together (Church and Miles, 1987; Malet et al., 2005; Mostbauer et al., 2018). Therefore, studying the association between debris flow events and climatic factors is crucial for predicting and early warning of debris flows. Although many previous studies have been conducted, problems still exist in the effective prediction of debris flows' initiation in a certain area. Therefore, further research is required to minimize casualties and economic losses.

Most of those methods applied to predict debris flows are derived from the empirical intensity-duration (ID) threshold model used in landslide prediction. This method is used to identify typical rainfall characteristics such as intensity or duration within a certain period time that trigger debris flows (Caine, 1980; Copeland, 2009; Guzzetti et al., 2007; Johnson and Sitar, 1990; Zhang et al., 2020). Empirical rainfall thresholds were calculated from historical databases and rely on observed correlations between rainfall amount and debris flows occurrences (Guzzetti et al., 2008; Meyer et al., 2012; Nikolopoulos et al., 2014). However, rainfall is not the only factor that causes debris flows (Pavlova et al., 2014). Undoubtedly, there is a certain degree of uncertainty in determining rainfall thresholds, and as an empirical method, the inconsistency in basic data can often increase uncertainty. Therefore, the researchers have tried to solve these problems by complementing the rainfall threshold information on probability models (Frattini et al., 2010). Walder (1995) first analyzed the impact of temperature on the triggering of debris flows in the Rainier Mountains by a simple conditional probability method. Jomelli et al. (2007) and Pavlova et al. (2014) used the logistic regression (LR) method to study the meteorological conditions of debris flows that occurred in the Alps under different environmental conditions. Many Bayesian probability models have been successfully applied to implement early warning of debris flows in Austria and other Alpine regions (Prenner et al., 2018; van den Heuvel et al., 2016). These models can effectively evaluate the impact of different meteorological parameters on the initiation of debris flows and also use probability thresholds to evaluate the susceptibility to debris flows (Jomelli et al., 2015; Kaitna et al., 2019; Mostbauer et al., 2018; Prenner et al., 2018; Turkington et al., 2016). The Bayesian method has been widely used in Alpine glacier regions, where most of the study areas were watersheds with high latitudes and a large proportion of glaciers, and contrastingly, it has been applied to many basins located in low latitudes with a small proportion of glaciers or no glacier. In the small (or non-) glacier basin around periglacial areas, the melting of ice and snow impacts the initiation of debris flows, but it is often ignored. Currently, research on the characteristics and early warning thresholds of debris flows in this kind of periglacial area are still quite limited.

Mount Gongga is located in the southeast of the Qinghai-Tibet Plateau in China. Many temperate glaciers are present in the area, and it is the largest modern glacier center in the Hengduan Mountains. The Hailuogou glacier on the eastern slope of Mount Gongga is the lowest modern temperate glacier in China. Its contraction can be regarded as a response to global warming, and significant changes in debris flow activity are caused by different climatic conditions (Turkington et al., 2016). In most cases, extreme rainfall is the greatest role in triggering debris flows, while in a few cases, it is due to other meteorological combination effects. Based on 32 years of meteorological data in the area, this study classifies the triggering type of debris flows through climatic conditions. The one-dimensional Bayesian method was used to analyze susceptibility to debris flows using different meteorological parameters, and the two-dimensional Bayesian method was used to calculate and obtain the initiation probability of debris flow in different modes. This study aims to analyze the impact of different climatic conditions on the initiation of periglacial debris flows and propose an early warning threshold for this area. Furthermore, these models provide a reference for early warning of periglacial debris flows in other areas.

\section{Study Area}

\subsection{Basin overview}

Mount Gongga ( $29.68 \mathrm{~N}, 101.98 \mathrm{E})$ is located in the center of the Hengduan Mountain in the southeast of Qinghai-Tibet Plateau. There are 72 temperate glaciers around Mount Gongga, with a total area of $255.1 \mathrm{~km}^{2}, 5$ of which glaciers have a length of more than $10 \mathrm{~km}$ each. Glacier changes in the region are highly sensitive to temperature changes. Mount Gongga is located at the Longmenshan structural belt-Xianshuihe fault system-Chuandian S-N tectonic 
zone junction with active neotectonics and frequent seismic activity. Since the Quaternary, glacier activity has intensified, causing the formation of many moraines on the bottom and sides of the valleys, thereby providing abundant sediment for debris flow development. Geomorphologically, the study area is characterized by the presence of high terrains, high mountains, and deep valleys. Differences in terrain height are large and, thus, provide the potential energy needed to form debris flows. The west slope of Mount Gongga has a subtropical plateau climate and experiences the southwest monsoon with low temperatures and little precipitation. And the east has a subtropical mountainous humid monsoon climate and is warm in winter and wet in summer. In this area, the annual average precipitation and temperature is $1862.5 \mathrm{~mm}$ and $4.5^{\circ} \mathrm{C}$ respectively. The cumulative average rainfall from May to September is approximately $1325.74 \mathrm{~mm}$, accounting for approximately $70 \%$ of the average annual rainfall. The abundant rainfall, snow, and ice melt in the area provided sufficient water sources of debris flows' initiation.

The Hailuogou (HLG) basin of the eastern slope of Mount Gongga is between $101^{\circ} 52^{\prime} \mathrm{E}-102^{\circ} 07^{\prime} \mathrm{E}$, and $29^{\circ} 31^{\prime} \mathrm{N}-29^{\circ} 37^{\prime} \mathrm{N}$. The highest altitude point of the basin is the peak of Mount Gongga at $7556 \mathrm{~m}$, and the lowest is at $1460 \mathrm{~m}$, and the snow line is approximately $5000 \mathrm{~m}$ (a.s.I.) (Liu et al., 2010 ). There are seven glaciers in the basin, among which glacier no. 3 is the largest, with an area of $24.84 \mathrm{~km}^{2}$ and the nadir of its ice tongue at $3000 \mathrm{~m}$ (a.s.I.). The smallest glacier (No. 7) is located in Guanjingtaixi (GJTX), with an area of only $0.09 \mathrm{~km}^{2}$. There are no glaciers covered in the Huangbengliu (HBLG) Basin, but a large snow-covered area in winter and spring and permanently snow-covered at high elevations. The moraines produced by the ancient and modern glaciers are widely distributed in the two channels: this may provide abundant sediment to initiate debris flows under the action of precipitation or meltwater. The HBLG and the GJTX are located on the left flank of the upper reaches of the main channel of the Hailuogou Gully. The HBLG is oriented northsoutheast, and the GJTX is oriented north-south. The bedrock in the area is composed of various Permian schists intercalated with quartzite, marble, slate, and crystalline limestone. The soil formed by weathering of this type of rock has a high content of clay particles and supports the formation of viscous debris flows.

\subsection{Debris flow history}

Guanjingtaixi (GJTX) and Huangbengliu (HBLG) in the Hailuogou periglacial area were chosen for the case study. The GJTX has a small glacier, and the HBLG has a part of firn (Fig. 1). During 1988-2019, debris flows were recorded in these areas on 14 days, and 6 of them were recorded in the two channels simultaneously. The first documented debris flow occurred in GJTX on July 8, 1989. On the afternoon of July 26 of the same year, debris flows occurred in HBLG and GJTX at the same time, with a total accumulation of more than 500,000 $\mathrm{m}^{3}$. On July 12,1990 , heavy rainfall caused a debris flow in HBLG. In the early morning of July 28,1995 , debris flow occurred in both HBLG and GJTX, and it went on for a long time. On August 11 of the same year, a new debris flow developed in HBLG due to moraine debris in the basin's upper reaches collapsed, feeding debris flow along the channel. On July 27,1996 , HBLG recorded a high-speed debris flow during a nearly full day of clear weather. Heavy rains on July 1 to 3, 1997, led to widespread flash floods and on July 4, debris flows occurred in the Hailuogou Basin, including in HBLG and GJTX. On August 1 and 15 of the same year, debris flows occurred in both gullies. Among them, the rainfall recorded on August 15 is the highest $91 \mathrm{~mm}$ in the history of the station. Intense rainfall on July 26,2003 , triggered debris flow in HBLG, which caused severe damage to the cableway in the scenic spot (Ruren et al., 2001; Ni et al., 2010). Due to continuous rainfall, large-scale debris flows occurred in Gongga Mountain on August 11, 2005, including HBLG. In 2010, the temperature in the study area reached the highest in recent years, debris flow respectively triggered on July 17th and July 31 st in 2010 at HBLG. The latest debris flow of HBLG occurred on July 29, 2019, with the total amount of moraine soil exceeding 20,000 cubic meters.

Debris flows occurred at the same time in adjacent channel are usually triggered by the same rainfall event or an extreme temperature event in the area. Therefore, it is better to count several debris flows that occurred simultaneously as a single event while historically accounting for debris flow events. For example, debris flows occurred in both channels on July 26,1989 . If we calculate this for each channel separately, it will be counted as two events, but we only recorded one debris flow event because they were triggered by the same set of climatic conditions, ensuring that the number of debris flow events does not exceed the number of extreme rainfall events. Therefore, the debris flow events mentioned in this work do not refer to the event in a particular gully but to the event days (14 days) with recorded debris flow events.

For the purposes of this study, we adopted the following methods: (i) classifying debris flows according to the influence degree of meteorological events with different exceedance probabilities; (ii) analysis of the sensitivity of debris flows to different climatic conditions by using the one-dimensional Bayesian method; and (iii) analysis of debris flow susceptibility caused by the effect of multiple climatic conditions through the two-dimensional Bayesian method and proposing an early warning threshold.

\section{Data And Methodology}

\subsection{Available data}

The meteorological data used in this study was collected from the Gongga Alpine Ecosystem Observation Station (GAEOS) of the Chinese Academy of Sciences. The GAEOS meteorological stations are at $3000 \mathrm{~m}$, near the glacier tongue on the Gongga Mountain, which has been operated in 1988 . The data collected by this station include precipitation, air temperature, wind speed, humidity, and solar station, et al. Among them, data onto 1998-2002 are missing due to the equipment replacement (we fitted monthly data for missing years). The original time step of data acquisition precipitation and air temperature is hourly. But in the follow-up study, we use rainfall and air temperature variable for research. The precipitation here is almost made up by rainfall since we found nearly no snowfall at 3000 m elevation after June.

There is also a runoff station in HBLG, and the runoff data were available from 1990 to 2008 . However, many runoff data are missing due to the impact on debris flow; we only use runoff data for auxiliary analysis.

\subsection{Methods}




\subsubsection{Debris flow trigger analysis}

Due to all the debris flow days were only recorded in summer (June-August), we restricted the definition of probabilities of the years which recorded debris flows, i.e., from 1 June to 31 August 1988-2019. Therefore, all the probabilities after that in this paper are depending on this duration.

As debris flows often occur on days of extreme meteorology, we categorize the starting pattern of the periglacial debris flows based on an extreme meteorological event on a particular day. To make out potentially trigger mechanism for debris flows initiation, we discussed the hydrometeorological variables at different time scales while debris flows occurred. There were some observed variables, like daily rainfall $R\left(\mathrm{~mm}^{-1}\right)$, daily mean air temperature $T\left({ }^{\circ} \mathrm{C}\right)$, daily runoff $Q\left(\mathrm{~mm}^{3} \mathrm{~d}^{-1}\right)$, as well as calculated variables as antecedent rainfall $(A R 3, A R 7, A R 15, A R 30)\left(\mathrm{mm} \mathrm{d}^{-1}\right)$, and mean temperature $(M T 3, M T 7$, $M T 15, M T 30)\left({ }^{\circ} \mathrm{C}\right)$. The antecedent rainfall here is considered to be a function of degressive index and time, which can be calculated by the following equation(Bruce and Clark, 1966):

$$
R_{a}=\sum_{i=1}^{n} R_{\gamma}(K)
$$

where $R_{a}=$ the effective antecedent rainfall fell during $i$ days before debris flow occurred $(\mathrm{mm}), K=$ the degressive index which is 0.84 adopted widely in the Southwest China (Cong et al., 2006) at present, $R_{i}=$ the total rainfall during $i$ days before debris flow occurred $(\mathrm{mm})$.

To promote a more intuitive comparison of the variables, we defined the classes of exceedance probabilities $P_{e}$ for the independent variables as follows: $1 \geq$ $P_{e}>0.5$ equaled to high, $0.5 \geq P_{e}>0.1$ was moderate, $0.1 \geq P_{e}>0.01$ was low, and $P_{e} \leq 0.01$ as very low corresponds to extreme events of rainfall and temperature. These exceedance probabilities of the observed and calculated data were used to efficient analyses whether there are different dominant trigger mechanisms of debris flow. The $P_{e} \leq 0.01$ in this paper equaled to $R \geq 43.2 \mathrm{~mm} \mathrm{~d}^{-1}$ and $T \geq 16.4^{\circ} \mathrm{C}$, respectively.

Using the $P_{e}$ of the recorded variables daily rainfall $R$ and daily air temperature $T$, together with eight calculated variables at the event days, then relative assessments of which variable played the greatest role in triggering a debris flow and how the relative impact of those variables changes as time goes on depend on the meteorological conditions at that time. While a certain variable reaches the value with $1 \geq P_{e}>0.5$, it can be considered that this variable is hard to trigger debris flow. In comparison, it was accordingly to have an extremely high relevance for triggering debris flow on days with extremely low exceedance probabilities $\left(P_{e} \leq 0.01\right)$ (Mostbauer et al., 2018).

\subsubsection{One-dimensional analysis}

Conditional probability refers to the probability of occurrence of event $A$ (hereinafter referred to as debris flows) under event $B$ (a certain scale of rainfall, temperature, or other variables) (Casella and Berger, 2002; Stoffel et al., 2005; Walder and Driedger, 1995). Conditional probability can be expressed as $P(A / B)$, which can be understood as "the probability of occurrence of debris flows $(A)$ given rainfall $(B)$." Conditional probability can be directly applied to the Bayes' theorem (Bayes, 1763) expressed by the following formula:

$R A \mid B)=\frac{R(B \mid A) P(A)}{R(B)}$

where $P(B \mid A)=$ the probability of occurrence of $B$ after a given $A$ (also called likelihood), that is, the probability of observing a $B$-level rainfall event when a debris flows occurs; $P(A)=$ the prior probability of $A$, that is, the probability that a debris flows can occur regardless of whether a $B$-level rainfall event occurs; $P(B)=$ the marginal probability of $B$, that is, the probability of observing a B-level rainfall regardless of whether debris flows occurs; $P(A / B)=$ the probability of occurring $A$ after given $B$ (also known as the posterior probability), i.e., the probability of debris flows observed when a $B$-level rainfall event occurred.

One-dimensional Bayesian analysis can be effectively used to assess the importance of variable $B$ in explaining an event (Berti et al., 2012). The analysis was performed using the data set presented in Sect. 3.1. The marginal rainfall probability $P(B)$ was calculated from the selected 2300 rainfall and temperature events, and $P(A / B)$ was calculated using the rainfall conditional probability of the 14 debris flow events. The prior probability of debris flows was $P(A)=14 / 2300=0.006$. Ten explanatory variables were tested: event rainfall $(R)$, antecedent rainfall in the previous $n$ days $(A R 3, A R 7, A R 14, A R 30)$, and event mean temperature $(T), n$ days mean temperature (including $M T 3, M T 7, M T 14, M T 30$ ) (the last day of the total and the average is considered the day when the debris flows occurred).

\subsubsection{Two-dimensional analysis}

The formula of two-dimensional Bayes' theorem can be presented by:

$R A \mid B, C)=\frac{R B, C \mid A) R(A)}{R(B, C)}$

where the symbols $B$ and $C$ indicate specific values with two variables. For instance, if $B$ is daily rainfall $(R), C$ is the mean daily temperature ( $T$ ). Eq. (3) represents the probability of debris flows occurring at a given rainfall and temperature.

Any pair of variables (such as daily rainfall and daily average temperature) can be considered in the two-dimensional Bayesian analysis, and the posterior debris flows probability $P(A / B)$ is compared with the prior debris flows probability $P(A)$ to assess their importance. Although the Bayesian method can be used to deal with the multi-dimensional analysis of the influence of $n$ variables like rainfall intensity, rainfall duration, and antecedent rainfall on the initiation of debris flows, it has limitations of data scarcity. Moreover, multi-dimensional data visualization itself has several limitations. Therefore, this research is limited to the two-dimensional situation. 
The two-dimensional Bayesian method considers the influence of rainfall and temperature work together on triggering debris flows and expresses the probability of its occurrence under the conditional probability of all the considered conditions. It is difficult to draw a clear dividing line between rainfall and temperature as the cause of debris flows by using this method. However, it is possible to identify a reasonable threshold based on the probability of the occurrence of debris flows. Moreover, such methods can be dynamically updated with the addition of new data (Berti et al., 2012). For actual forecasting and early warning, the cost of missing an event and raising a false alarm must be considered simultaneously.

\section{Results}

\subsection{Classification of debris flow events}

The values of hydrometeorological variables at the event days were chosen from the observed and calculated time series. There were 6 days (DF 1, 3, 5, 7, 8, 9) with debris flows observed rainfall exceeded $P=43.2 \mathrm{~mm} \mathrm{~d}^{-1}$, equivalent to a rainfall event with $P_{e} \leq 0.01$ over the research duration. Besides, rainfall recorded of 4 events (DF 2,4,10,14) reached moderate exceedance probability $0.01<P_{e}<0.1\left(\sim 23.4 \mathrm{~mm} \mathrm{~d}^{-1}\right)$. And 3 event days (DF 6, 11, 12) rainfall recorded with $0.1<P_{e}<0.5$, while only 1 day (DF13) nearly no rainfall was recorded. For all calculated antecedent rainfall, most variables of antecedent rainfall were $0.1<P_{e}<0.5$ and $P_{e}>0.5$, and only the exceedance probability of DF7's antecedent rainfalls reached $P_{e}<0.01$.

About variables of daily mean air temperature, there were only 2 event days (DF4, DF13) with a high probability of $0.01<P_{e}<0.1\left(14.6 \sim 16.4^{\circ} \mathrm{C}\right)$. Other exceedance probabilities of daily mean air temperature $T$ not reached 0.01 , especially DF5 occurred with $P_{e}>0.5$. However, it can be found that all the exceedance probabilities of $M T 3$ were $P_{e}<0.5$, among them, 3 events (DF $\left.2,6,14\right)$ reached $0.01<P_{e}<0.1$, and DF13 reached $P_{e}<0.01$ from the calculated temperature variables. Other calculated variables of temperature like $M T 7, M T 14$, and $M T 30$ corresponded to $3,1,2$, respectively, times high exceedance probability events with $0.01<P_{e}<0.1$.

The above exceedance probabilities of variables on the event days allowed us to identify the different relevance to different variables of rainfall and temperature for triggering the recorded events on the 14 event days and to classify the initiation class base on the variable which plays the most significant role in triggering debris flows (Table 1). The highest correlation between the observed and calculated variable of rainfall and temperature was taken as the main contributor, and the contribution degrees were expressed according to the different probability grades in the variable. Among them, $P_{e} \leq 0.01$ represents extremely high correlation (+++), $0.01<P_{e} \leq 0.1$ represents high correlation $(++), 0.1<P_{e} \leq 0.5$ represents medium correlation $(+)$, and $0.5<P_{e} \leq 1$ represents a low correlation.

By comparing the degree of contribution to different variables, it is found that the debris flow events dominated by rainfall accounted for 7 of the 14 event days (50\%), while the temperature as the leading cause accounted for 2 event days (14\%), 5 event days (36\%) caused by the same contribution degree of rainfall and temperature. On the 6 of 7 event days, rainfalls caused most with daily rainfall $R>43.2 \mathrm{~mm} \mathrm{~d}^{-1}$ observed probably to have an extremely high relevance to triggering the debris flows. Most of the exceedance probabilities of the values of $T$ for these events reached $0.1<P_{e} \leq 0.5$, indicate that there are some moderately relevant additional contributions to runoff and increase the initiate water of debris flows. For example, the rainfall on 12 July 1990 reached extremely $64.5 \mathrm{~mm}$ with falling temperature for a few days, a dramatic runoff was observed, and debris flow occurred (Fig. 2a). Another one of 7 event days caused by high rainfall $R=41.8 \mathrm{~mm}^{-1}\left(0.01<P_{e} \leq 0.1\right)$ and moderate temperatures $\left(0.1<P_{e} \leq 0.5\right)$. High-intensity rainfall played the dominant role in those 7 events, while temperature played a minor role.

It is found that DF6 and DF13 occurred with little antecedent, which exceedance probabilities were $0.1<P_{e} \leq 0.5$; however, the triggered water is also common rainfall, DF6 occurred with recorded daily rainfall $R=8.7 \mathrm{~mm}^{-1}$ and DF13 with $R=0.2 \mathrm{~mm} \mathrm{~d}^{-1}$. Especially the daily rainfall of DF13 nearly no measured rainfall but debris flow also triggered (Fig. 2b). According to the recorded temperature variables of them, we found that the 3 days mean temperature $\mathrm{MT3}$ of DF6 was $14.7^{\circ} \mathrm{C}\left(0.01<P_{e} \leq 0.1\right)$ and of DF13 was $16.1^{\circ} \mathrm{C}\left(P_{e} \leq 0.01\right)$. Their recorded daily temperature was a medium and high correlation, respectively. Therefore, those two events were triggered by the meltwater caused by rising high temperatures, and the rainfall played only a minor role.

Besides, there were 5 events triggered by the same degree of rainfall and temperature, including DF2, 4, 11, 12, 14. Among them, DF11 and 12 occurred with medium rainfall and temperature. From Fig. 2c, we found that this event was triggered by the combination of long-lasting rainfall and rising temperature; variables with moderate exceedance probability $\left(0.1<P_{e} \leq 0.5\right)$ can also cause debris flow. DF2, 4,14 were triggered by the combination of high rainfall and temperature with low exceedance probability $\left(0.01<P_{e} \leq 0.1\right)$. The antecedent rainfall of DF4 showed a low correlation of debris flow, but the daily rainfall and temperature, which reached $0.01<P_{e} \leq 0.1$, caused debris flow (Fig. 2 d).

It can be concluded that it is more difficult to trigger periglacial debris flows by the influence of high temperature than rainfall in this area, and debris flows triggered by the combination of rainfall and temperature tend to have a greater impact and faster speed. At the same time, we plot the distribution of variables to compare the difference between 3 triggering modes (Fig. 3). It is found that there are obvious distribution differences in daily rainfall ( $R$ ), daily temperature $(T)$, and 3 days mean temperature (MT3) of 3 different triggering modes. 
Table 1

The 14 recorded debris flow events in Hailuogou since 1988. For each individual variable for a given event, bold and italic values indicate an extremely low occurrence probability $\left(P_{e} \leq 0.01\right)$, bold values as a low occurrence probability $\left(0.01<P_{e} \leq 0.1\right)$; italic values as moderate occurrence probability $\left(0.1<P_{e} \leq\right.$ $0.5)$ and normal values as a high occurrence probability $\left(0.5<P_{e} \leq 1\right)$.

\begin{tabular}{|c|c|c|c|c|c|c|c|c|c|c|c|c|c|}
\hline \multirow[t]{2}{*}{$\begin{array}{l}\text { Event } \\
\text { No. }\end{array}$} & \multirow[t]{2}{*}{ Date } & \multicolumn{5}{|c|}{ Rainfall/mm d ${ }^{-1}$} & \multicolumn{5}{|c|}{ Temperature $/{ }^{\circ} \mathrm{C}$} & \multicolumn{2}{|c|}{$\begin{array}{l}\text { Contribution } \\
\text { degree }\end{array}$} \\
\hline & & rain_d & rain_3d & rain_7d & rain_14d & rain_30d & temp_d & temp_3d & temp_7d & temp_14d & temp_30d & $R$ & $T$ \\
\hline 1 & $1989 / 7 / 8$ & 57.6 & 7.8 & 15.2 & 35.6 & 38.3 & 13.1 & 13.5 & 10.9 & 9.6 & 10.3 & +++ & + \\
\hline 3 & 1990/7/12 & 64.5 & 3.6 & 5.4 & 17.5 & 20.5 & 13.2 & 14.1 & 14.1 & 13.6 & 12.3 & +++ & ++ \\
\hline 5 & $1995 / 8 / 11$ & 44.7 & 19.0 & 41.1 & 56.6 & 59.8 & 11.8 & 13.9 & 13.5 & 13.6 & 13.6 & +++ & ++ \\
\hline 7 & $1997 / 7 / 4$ & 43.3 & 81.6 & 97.8 & 103.8 & 110.4 & 13.5 & 13.7 & 12.6 & 11.8 & 10.2 & +++ & + \\
\hline 8 & $1997 / 8 / 1$ & 48.0 & 19.6 & 37.9 & 44.3 & 48.6 & 12.8 & 12.9 & 12.8 & 12.4 & 11.9 & +++ & + \\
\hline 9 & 1997/8/15 & 91.0 & 4.1 & 15.3 & 27.3 & 31.3 & 12.4 & 13.4 & 12.5 & 13.6 & 12.9 & +++ & + \\
\hline 10 & $2003 / 7 / 26$ & 41.8 & 25.0 & 37.6 & 42.0 & 47.5 & 13.5 & 14.0 & 12.3 & 13.5 & 12.6 & ++ & + \\
\hline 6 & $1996 / 7 / 27$ & 8.7 & 17.6 & 34.1 & 47.3 & 52.9 & 14.5 & 14.7 & 12.8 & 12.2 & 11.8 & + & ++ \\
\hline 13 & $2010 / 7 / 31$ & 0.2 & 23.4 & 48.9 & 59.8 & 63.8 & 16.3 & 16.1 & 14.7 & 13.7 & 13.7 & + & +++ \\
\hline 2 & $1989 / 7 / 26$ & 42.8 & 21.5 & 36.8 & 54.4 & 60.4 & 12.4 & 14.4 & 15.0 & 14.0 & 11.9 & ++ & ++ \\
\hline 4 & $1995 / 7 / 28$ & 31.6 & 0.9 & 20.4 & 36.3 & 39.2 & 15.2 & 14.2 & 13.8 & 13.6 & 12.3 & ++ & ++ \\
\hline 11 & $2005 / 8 / 11$ & 17.4 & 28.3 & 50.7 & 63.6 & 66.0 & 12.8 & 12.3 & 11.9 & 12.9 & 12.8 & + & + \\
\hline 12 & $2010 / 7 / 17$ & 15.6 & 13.2 & 31.3 & 41.2 & 49.3 & 12.7 & 14.0 & 12.9 & 13.5 & 12.6 & + & + \\
\hline 14 & $2019 / 7 / 29$ & 25.8 & 5.9 & 18.3 & 31.1 & 36.1 & 13.5 & 14.5 & 13.4 & 13.5 & 12.0 & ++ & ++ \\
\hline
\end{tabular}

\subsection{One-dimensional Bayesian probability}

Our study has shown that periglacial debris flows are more sensitive to rainfall than temperature.

The results of the one-dimensional Bayesian analysis are shown in Fig. 4 and Fig. 5. The left side of the two figures (a, c, e, g, and i) compare the initial rainfall/temperature of the debris flows and the overall frequency distribution, namely $P(B \mid A)$ and $P(B)$, the right side of the figures $(\mathrm{b}, \mathrm{d}, \mathrm{f}, \mathrm{h}$, and $\mathrm{j})$ shows the probability of debris flow occurrence $P(A / B)$. The difference between $P(B / A)$ and $P(B)$ is large, and $P(A / B)$ is higher, indicating that the significance of the variable under consideration is higher. The two figures show that the probability of debris flows increased with the event's severity, and the rainfall variable is more significant than temperature. The triggers for debris flows can be ranked as follows: $R>A R 3>A R 14>A R 7>A R 30>M T 3>M T 30>T>M T 7>M T 14$. Event daily rainfall $R$ is the most significant explanatory variable among these 10 variables capable of triggering a debris flow event as a single variable. When $R>30 \mathrm{~mm} \mathrm{~d}^{-1}, P(A / B)$ gradually increases. When $R>40 \mathrm{~mm} \mathrm{~d}^{-1}, P(A / B)$ reaches 0.2 , and when $R>60 \mathrm{~mm} \mathrm{~d}^{-1}, P(A / B)$ is as high as 0.33 . Here, the $P(A / B)$ reaches $100 \%$ when $R>90 \mathrm{~mm} \mathrm{~d}^{-1}$, because there was only 1 rainfall event (DF7's daily rainfall) recorded more than $90 \mathrm{~mm} \mathrm{~d}^{-1}$ and no other rainfall events recorded between 70 to $90 \mathrm{~mm} \mathrm{~d}^{-1}$. Among the temperature variables, MT3 is more significant in triggering debris flows confirming the finding of Paranunzio et al. (2014). When $M T 3>16^{\circ} \mathrm{C}$, the $P(A / B)$ value reaches the highest value of 0.06 .

\subsection{Two-Dimensional Bayesian probability}

The rainfall-3 days mean temperature threshold of periglacial debris flows is dynamic, and $P(A / R, M T 3) \approx 0.1$ can be selected as the early warning threshold of debris flows.

Two-dimensional Bayesian analyses refers to the conditional probability analyses of debris flow events given by two control variables. The variables should be selected from the variables with the highest explanatory in the one-dimensional Bayesian analysis. In this paper, it should be the event rainfall and antecedent rainfall in the previous 3 days, but these two variables have a high degree of coincidence, and therefore, we chose the parameters of event rainfall and 3 days mean temperature for analysis.

We connected the points with equal posterior probability $P(A / R, M T 3)$ of debris flows under different parameters into contour lines and plotted them in Fig. 6. It can be seen that when the 3 days mean temperature is lower than $11^{\circ} \mathrm{C}$ and no rainfall event occurs, the probability of debris flows is 0 . The probability of debris flows is also 0 when the rainfall is less than $8.7 \mathrm{~mm} \mathrm{~d}^{-1}$ and the 3 days mean temperature is $8^{\circ} \mathrm{C}$. The debris-free area shown in Fig. 6 includes all the points where $P(A / R, M T 3)=0$ because there is no rainfall in this area in the recorded meteorological conditions of debris flow outbreaks when $M T 3>8^{\circ} \mathrm{C}$ and rainfall $R>50 \mathrm{~mm} \mathrm{~d}^{-1}$, the probability of a debris flow outbreak reaches the highest value of 0.4 . 
Figure 6 provides a series of rainfall-3 days mean temperature probability values. The key task is selecting a conditional probability value (if any) as the debris flow warning threshold. In our observation, we can define $P(A / R, M T 3) \approx 0.1$ as the threshold for debris flows warning because at least a single variable has reached the critical value to cause extreme events on this line (rainfall). For example, when $M T 3 \approx 8, R$ is already higher than $23.4 \mathrm{~mm}^{-1}$ of low exceedance probability $0.01<P_{e}<0.1$ on this line.

\section{Discussion And Conclusions}

By analyzing the relationship between eight debris flows activities in the Hailuogou periglacial region and associated meteorological conditions, the following conclusions can be drawn from this study:

i. In the periglacial areas with few glaciers and snow-covered watersheds, debris flow in the area is affected by rain and Of the 14 debris flow event days, seven are attributable to high-intensity rainfall, two are mainly triggered by rising high temperature, and five are affected by high rainfall and temperature.

ii. Periglacial debris flow is more sensitive to The overall probability of the occurrence of a debris flow event depends by the parameters in the order of daily rainfall >antecedent rainfall 3 days $>$ antecedent rainfall 14 days $>$ antecedent rainfall 7 days $>$ antecedent rainfall 30 days $>3$ days mean temperature $>30$ days mean temperature $>$ daily temperature $>7$ days mean temperature $>14$ days mean temperature. If we consider only one parameter as the trigger, the probability of occurrence of debris flows is determined by these conditions: when the daily rainfall $R>40 \mathrm{~mm} d^{-1}$, the probability of a debris flow outbreak in this area is $20 \%$, when $R>60 \mathrm{~mm} \mathrm{~d}^{-1}$, the probability reaches $33.3 \%$; when the $M T 3>16^{\circ} \mathrm{C}$, the probability of a debris flow outbreak is $6 \%$.

iii. Based on the analysis of the data set, a contour map of the conditional probability of the periglacial debris flows caused by the rainfall-3-days mean temperature was plotted, and the conditional probability when $P(A / E, M T 3) \approx 0.1$ was defined as the threshold value, which can be used as the reference value for debris flows early warning in this region. For the high-intensity rainfall triggered debris flows, which are caused by heavy rainfall on the day of its occurrence, it is easier to discover and provide early warning, while in the cases of temperature triggered debris flows, a lower daily rainfall can also induce debris flows, and thus, early warning is difficult. Therefore, one should be alerted to identify the outbreak of debris flows caused by both rainfall and temperature to be able to provide early warning during actual monitoring.

Although some progress has been made in understanding the meteorological causes and prediction and early warning of debris flow outbreaks in the Mount Gongga periglacial area, some problems persist:

i. Our study is limited to only 14 days of occurrences of historical debris flows, and, likely, some events have not been As a result, the numbers of recorded debris flow events re incomplete, leading to unavoidable errors in the probability Therefore, more debris flows data must be added in future research to optimize the warning threshold of periglacial debris flows in this area.

ii. The triggering of periglacial debris flows is often the result of combined effects of meteorology, hydrology, and geomorphology (Jomelli et al., 2007; Stoffel et al., 2011; Borga et al., 2014). Our research focuses on the relationship between the outbreak of debris flows and rainfall and temperature without considering the impact of geomorphological conditions on the susceptibility to debris In future research, the influence of channel characteristics will be added to the analysis.

iii. Earthquakes can trigger debris flows, especially those accompanying extreme drought years, causing large-scale debris flow events (Chen et al., 2014). According to data available, an earthquake with a magnitude of $5.2 \mathrm{Mw}$ occurred in Shimian county, approximately $50 \mathrm{~km}$ away from Hailuogou, on June 9,1989 , which may be one of the reasons for the two consecutive debris flows in July of that year. Therefore, further studies shall consider combining seismic activity with climate change.

iv. As natural systems are affected by land use, land to cover, rainfall patterns, and human activities, changes in these will also affect the frequency of debris flows.

Therefore, our research is only appropriate for predicting, and early warning of debris flows by using hydrometeorological conditions within the study area.

\section{Abbreviations}

HLG: Hailuogou; GJTX: Guanjingtaixi; HBLG: Huangbengliu

\section{Declarations}

\section{Acknowledgments}

This research was funded by National Natural Science Foundation of China (2018YFC1505202; U20A20110;2019QZKK0902). And we thank the Gongga Alpine Ecosystem Observation and Research Station, CERN, China, for hydroclimatic data collection and field assistance. Finally, the authors wish to express their gratitude to anonymous reviewers and editor for their valuable comments that substantially improved this paper.

\section{Conflict of interest}

The authors declare no conflict of interest. 


\section{References}

1. Bayes, T., 1763. LII. An essay towards solving a problem in the doctrine of chances. By the late Rev. Mr. Bayes, FRS communicated by Mr. Price, in a letter to John Canton, AMFR S. Philosophical transactions of the Royal Society of London(53): 370-418.

2. Berti, M., Genevois, R., Simoni, A. and Tecca, P.R., 1999. Field observations of a debris flow event in the Dolomites. Geomorphology, 29(3-4): 265-274.

3. Berti, M., Martina, M.L.V., Franceschini, S., Pignone, S., Simoni, A. and Pizziolo, M., 2012. Probabilistic rainfall thresholds for landslide occurrence using a Bayesian approach. Journal of Geophysical Research: Earth Surface, 117(F4): n/a-n/a.

4. Bruce, J.P. and Clark, R.H., 1966. Introduction to Hydrometeorology. Pergamon Press, London.

5. Caine, N., 1980. The rainfall intensity-duration control of shallow landslides and debris flows. Geografiska annaler: series A, physical geography, 62(1-2): 23-27.

6. Casella, G. and Berger, R.L., 2002. Statistical inference, 2. Duxbury Pacific Grove, CA.

7. Chiarle, M., lannotti, S., Mortara, G. and Deline, P., 2007. Recent debris flow occurrences associated with glaciers in the Alps. Global and Planetary Change, 56(1-2): 123-136.

8. Church, M. and Miles, M.J., 1987. Meteorological antecedents to debris flow in southwestern British Columbia; Some case studies. GSA Reviews in Engineering Geology, 7: 63-80.

9. Cong, W., Pan, M., Li, T., Ren, Q. and Li, R., 2006. Quantitative analysis of critical rainfall-triggered debris flow. Chin J Rock Mech Eng, $25: 2808-2812$.

10. Copeland, E.A., 2009. Recent Periglacial Debris Flows from Mount Rainier, Washington, Oregon State University.

11. Decaulne, A., Sæmundsson, P. and Petursson, O., 2005. Debris flow triggered by rapid snowmelt: a case study in the glei. arhjalli area, northwestern iceland. Geografiska Annaler: Series A, Physical Geography, 87(4): 487-500.

12. Frattini, P., Crosta, G. and Sosio, R., 2010. Approaches for defining thresholds and return periods for rainfall-triggered shallow landslides. Hydrological Processes, 23(10): 1444-1460.

13. Glade, T., Crozier, M. and Smith, P., 2000. Applying probability determination to refine landslide-triggering rainfall thresholds using an empirical “Antecedent Daily Rainfall Model”. Pure and Applied Geophysics, 157(6-8): 1059-1079.

14. Guzzetti, F., Peruccacci, S., Rossi, M. and Stark, C.P., 2007. Rainfall thresholds for the initiation of landslides in central and southern Europe. Meteorology and atmospheric physics, 98(3-4): 239-267.

15. Guzzetti, F., Peruccacci, S., Rossi, M. and Stark, C.P., 2008. The rainfall intensity-duration control of shallow landslides and debris flows: an update. Landslides, 5(1): 3-17.

16. Johnson, K.A. and Sitar, N., 1990. Hydrologic conditions leading to debris-flow initiation. Canadian Geotechnical Journal, $27(6): 789-801$.

17. Jomelli, V., Pavlova, I., Eckert, N., Grancher, D. and Brunstein, D., 2015. A new hierarchical Bayesian approach to analyse environmental and climatic influences on debris flow occurrence. Geomorphology, 250: 407-421.

18. Kaitna, R., Prenner, D., Braun, M. and Hrachowitz, M., 2019. Hydro-meteorological trigger conditions of debris flows in Austria, Association of Environmental and Engineering Geologists; special publication 28. Colorado School of Mines. Arthur Lakes Library.

19. Liu, Q., Liu, S., Zhang, Y., Wang, X., Zhang, Y., Guo, W. and Xu, J., 2010. Recent Shrinkage and Hydrological Response of Hailuogou Glacier, A Monsoon Temperate Glacier on the East Slope of Mount Gongga, China. Journal of Glaciology, 56(196): 215-224.

20. Malet, J.P., Laigle, D., Remaître, A. and Maquaire, O., 2005. Triggering conditions and mobility of debris flows associated to complex earthflows. Geomorphology, 66(1-4): 215-235.

21. Matsuura, S., Okamoto, T., Asano, S. and Matsuyama, K., 2013. Characteristics of meltwater and/or rainfall regime in a snowy region and its effect on sediment-related disasters. Bulletin of Engineering Geology and the Environment, 72(1): 119-129.

22. Meyer, N.K., Dyrrdal, A.V., Frauenfelder, R., Etzelmüller, B. and Nadim, F., 2012. Hydrometeorological threshold conditions for debris flow initiation in Norway. Natural Hazards and Earth System Sciences, 12(10): 3059-3073.

23. Mostbauer, K., Kaitna, R., Prenner, D. and Hrachowitz, M., 2018. The temporally varying roles of rainfall, snowmelt and soil moisture for debris flow initiation in a snow-dominated system. Hydrology and Earth System Sciences, 22(6): 3493-3513.

24. Nikolopoulos, E.I., Crema, S., Marchi, L., Marra, F., Guzzetti, F. and Borga, M., 2014. Impact of uncertainty in rainfall estimation on the identification of rainfall thresholds for debris flow occurrence. Geomorphology, 221: 286-297.

25. Osanai, N., Shimizu, T., Kuramoto, K., Kojima, S. and Noro, T., 2010. Japanese early-warning for debris flows and slope failures using rainfall indices with Radial Basis Function Network. Landslides, 7(3): 325-338.

26. Pavlova, I., Jomelli, V., Brunstein, D., Grancher, D., Martin, E. and Déqué, M., 2014. Debris flow activity related to recent climate conditions in the French Alps: A regional investigation. Geomorphology, 219: 248-259.

27. Pavlova, I., Jomelli, V., Grancher, D., Brunstein, D. and Vrac, M., 2011. Debris flow occurrence and meteorological factors in the French Alps: A regional investigation, 5th International Conference on debris-flow hazards mitigation: Mechanics, prediction, and assessment, pp. $127-134$.

28. Prenner, D., Kaitna, R., Mostbauer, K. and Hrachowitz, M., 2018. The value of using multiple hydrometeorological variables to predict temporal debris flow susceptibility in an alpine environment. Water Resources Research, 54(9): 6822-6843.

29. Stoffel, M., Lièvre, I., Conus, D., Grichting, M.A., Raetzo, H., Gärtner, H.W. and Monbaron, M., 2005. 400 years of debris-flow activity and triggering weather conditions: Ritigraben, Valais, Switzerland. Arctic, Antarctic, and Alpine Research, 37(3): 387-395. 
30. Turkington, T., Remaître, A., Ettema, J., Hussin, H. and van Westen, C., 2016. Assessing debris flow activity in a changing climate. Climatic Change, 137(1-2): 293-305.

31. van den Heuvel, F., Goyette, S., Rahman, K. and Stoffel, M., 2016. Circulation patterns related to debris-flow triggering in the Zermatt valley in current and future climates. Geomorphology, 272: 127-136.

32. Walder, J.S. and Driedger, C.L., 1995. Frequent outburst floods from South Tahoma Glacier, Mount Rainier, USA: relation to debris flows, meteorological origin and implications for subglacial hydrology. Journal of Glaciology, 41(137): 1-10.

33. Wilson, R.C. and Wieczorek, G.F., 1995. Rainfall thresholds for the initiation of debris flows at La Honda, California. 33(3): 106A-106A.

34. Zhang, S., Xu, C., Wei, F., Hu, K., Xu, H., Zhao, L. and Zhang, G., 2020. A physics-based model to derive rainfall intensity-duration threshold for debris flow. Geomorphology, 351: 106930.

\section{Figures}

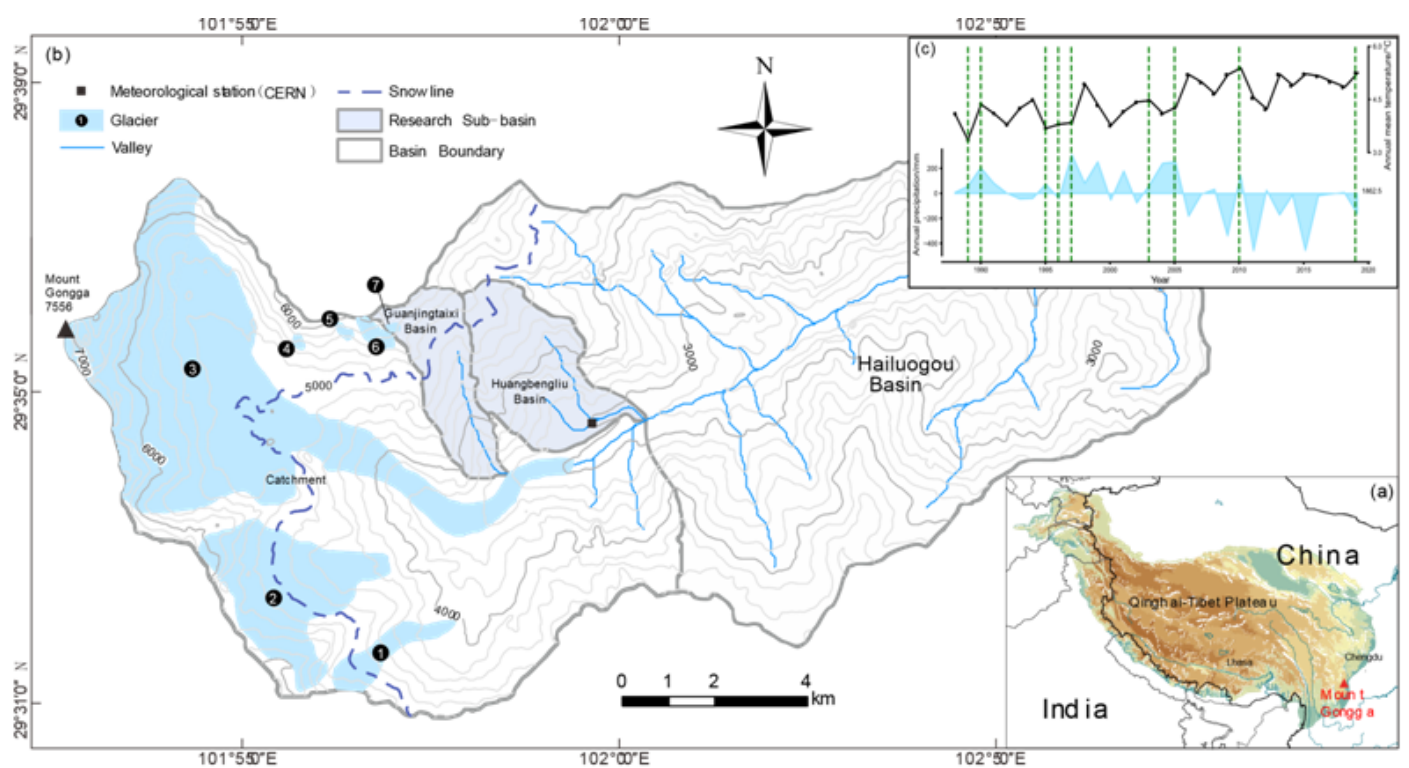

\section{Figure 1}

Map showing HLG catchment location (a), glacier distribution (b), and annual climate change (c). The green lines in (c) represent the years which recorded debris flow event. 

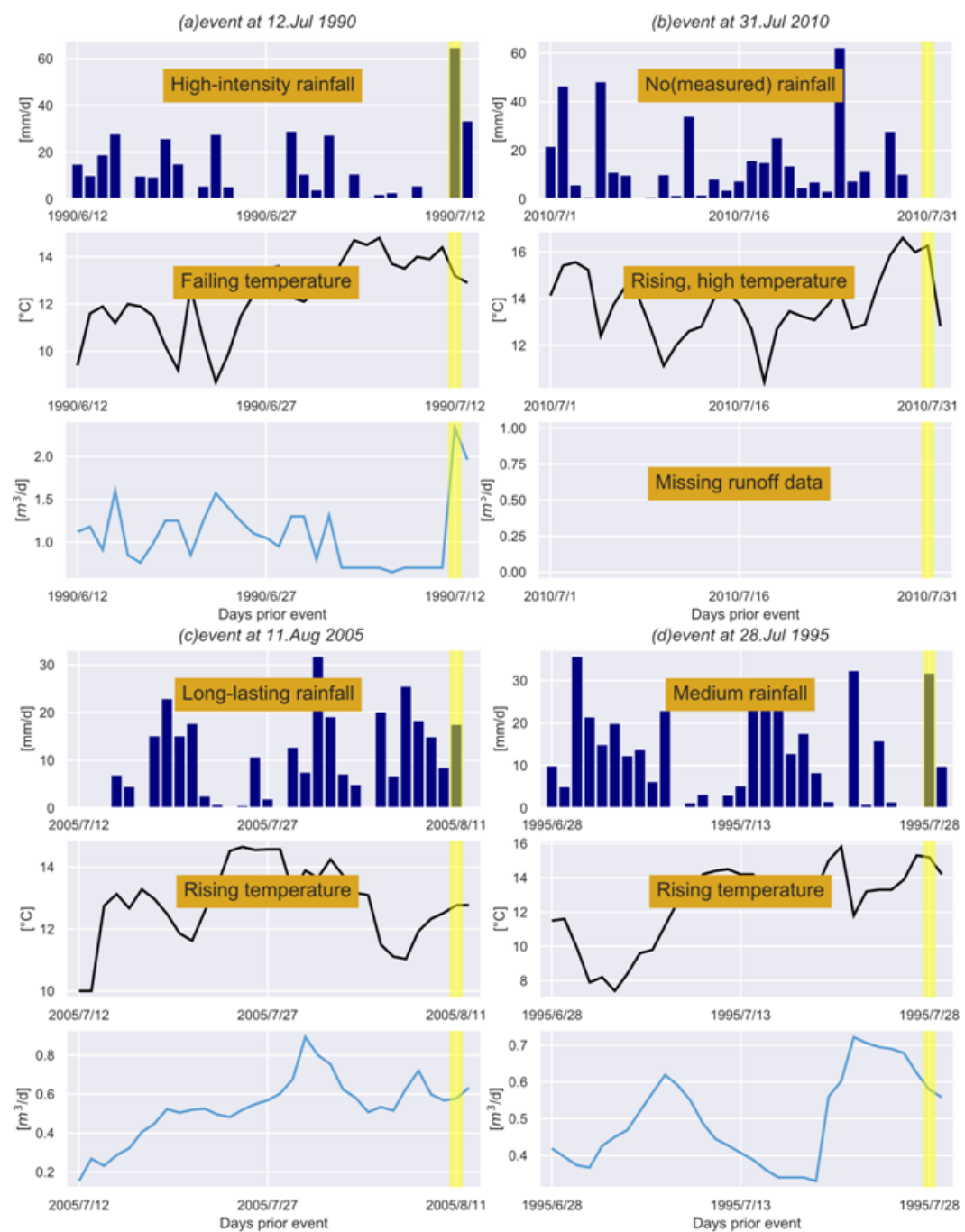

Figure 2

Examples of the observed hydrometeorological variables for the $3000 \mathrm{~m}$ station, including station rainfall, air temperature, and observed runoff. (a) the debris flow event on 12 July 1990, which may be interpreted as high-intensity rainfall; (b) on 31 July 2010, which suggests being intense snowmelt induced by high temperature; (c-d)events may be triggered by the interaction of long-lasting (or short-medium) rainfall and rising temperature.
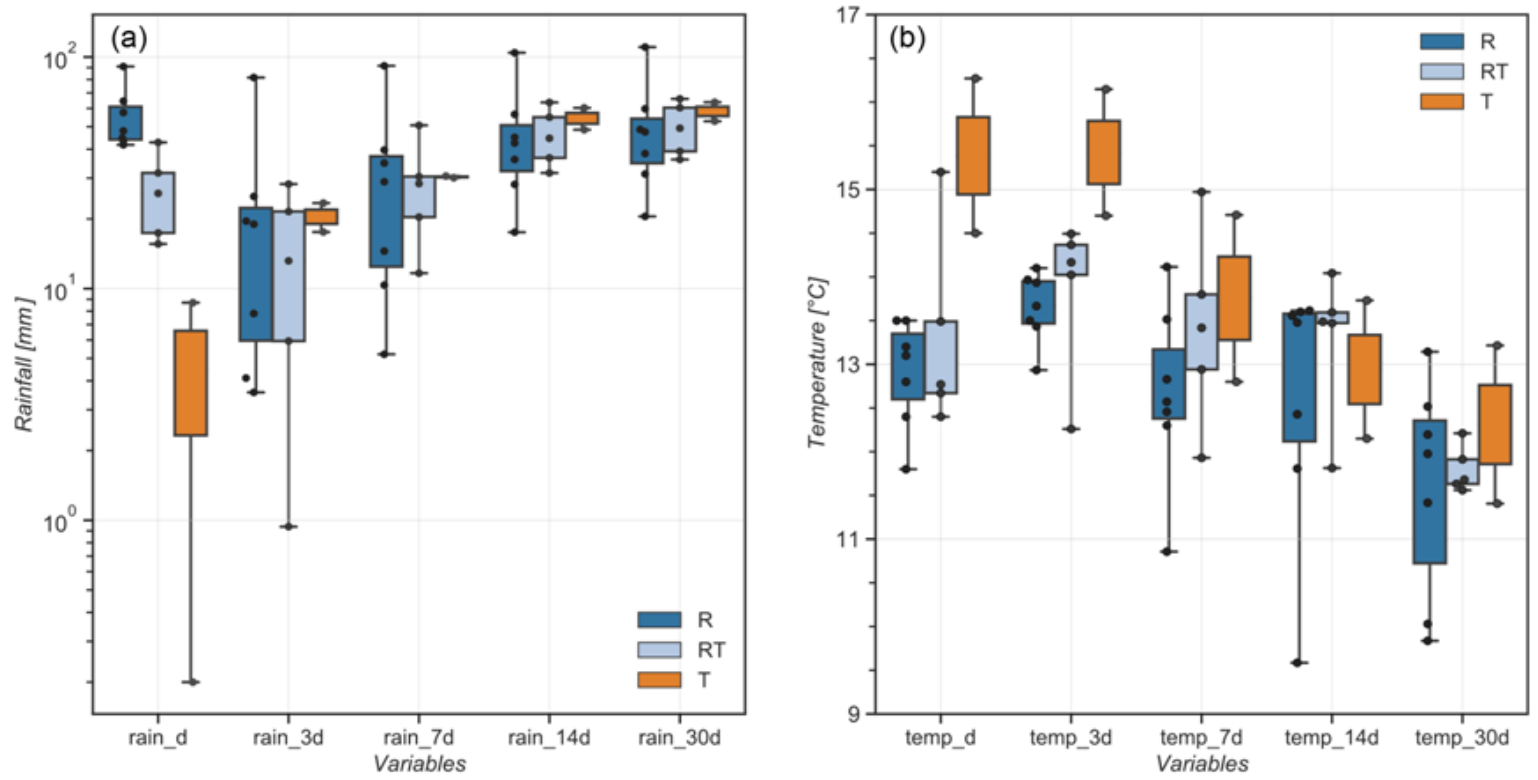

Figure 3 
Distribution of rainfall variables (a) and temperature variables $(b)$ for each trigger class $(R=$ rainfall triggered; $T=$ temperature triggered; $R T=$ rainfall and temperature triggered together).
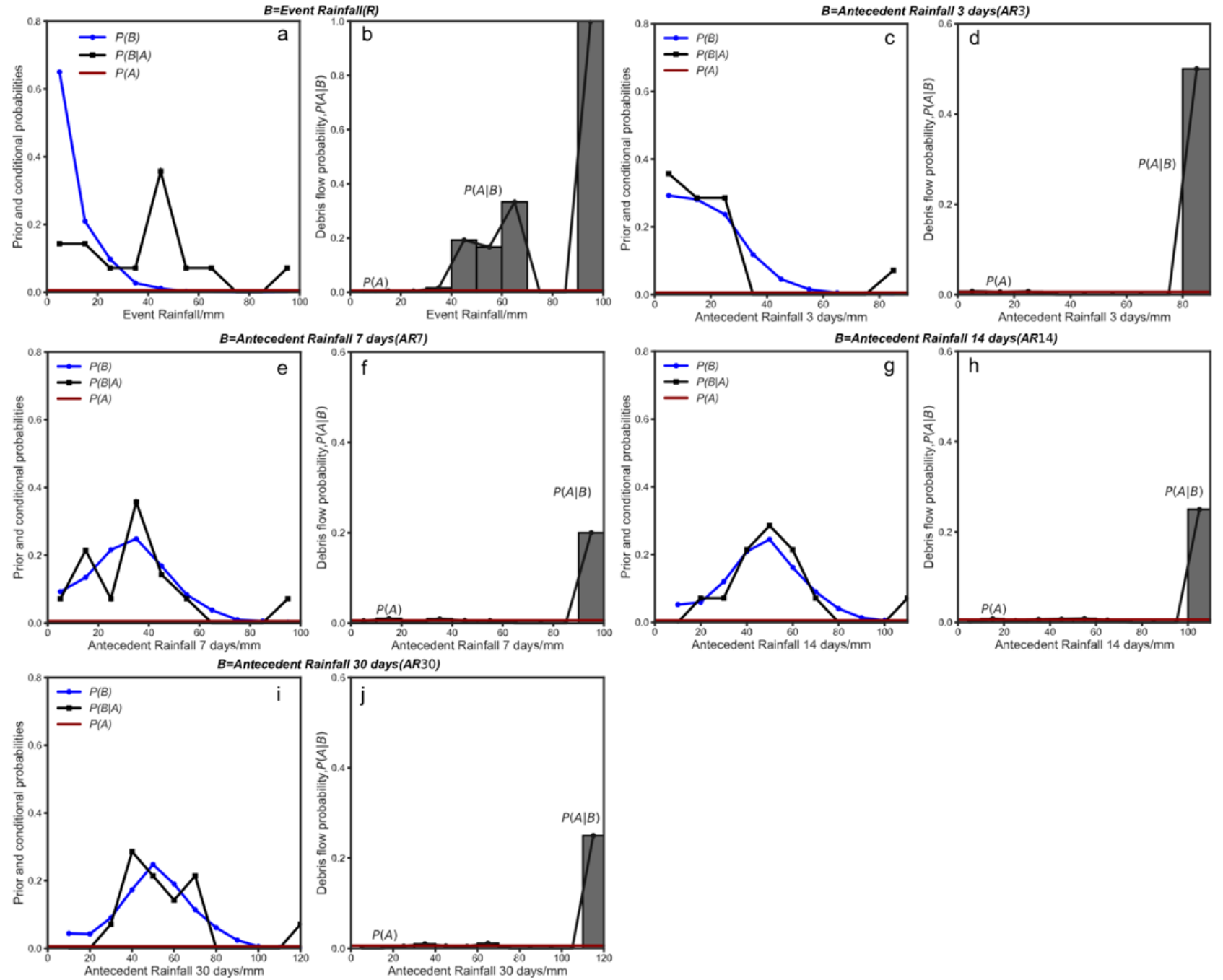

Figure 4

One-dimensional Bayesian analysis of the 3000-m station data set. Two different rainfall variables are considered: (a and b) event rainfall and (c - j) antecedent rainfall in the previous days. 

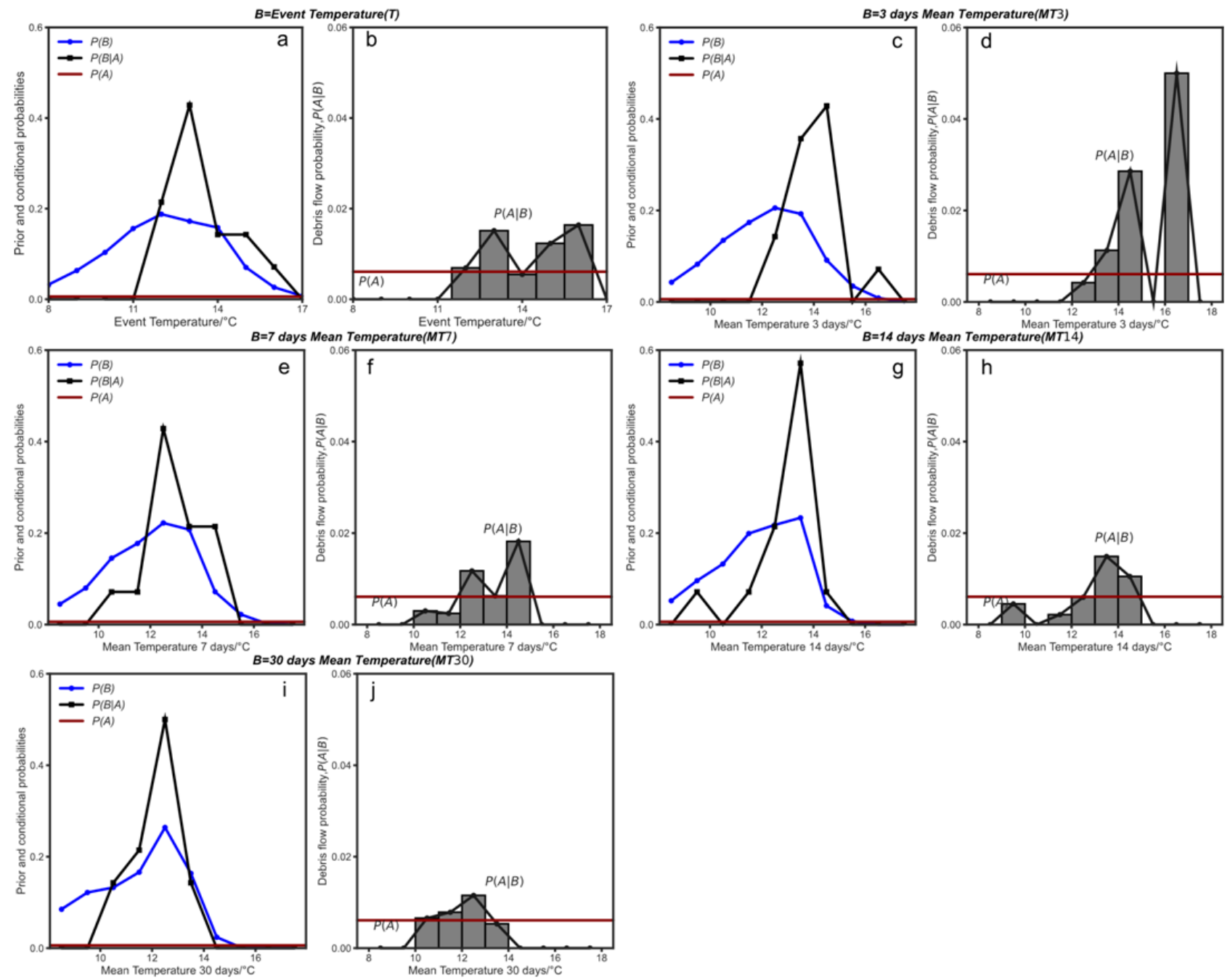

Figure 5

One-dimensional Bayesian analysis of the $3000 \mathrm{~m}$ station data set considering (a and b) event temperature and (c - j) 3 days mean temperature. Symbols are the same as in Fig. 4.

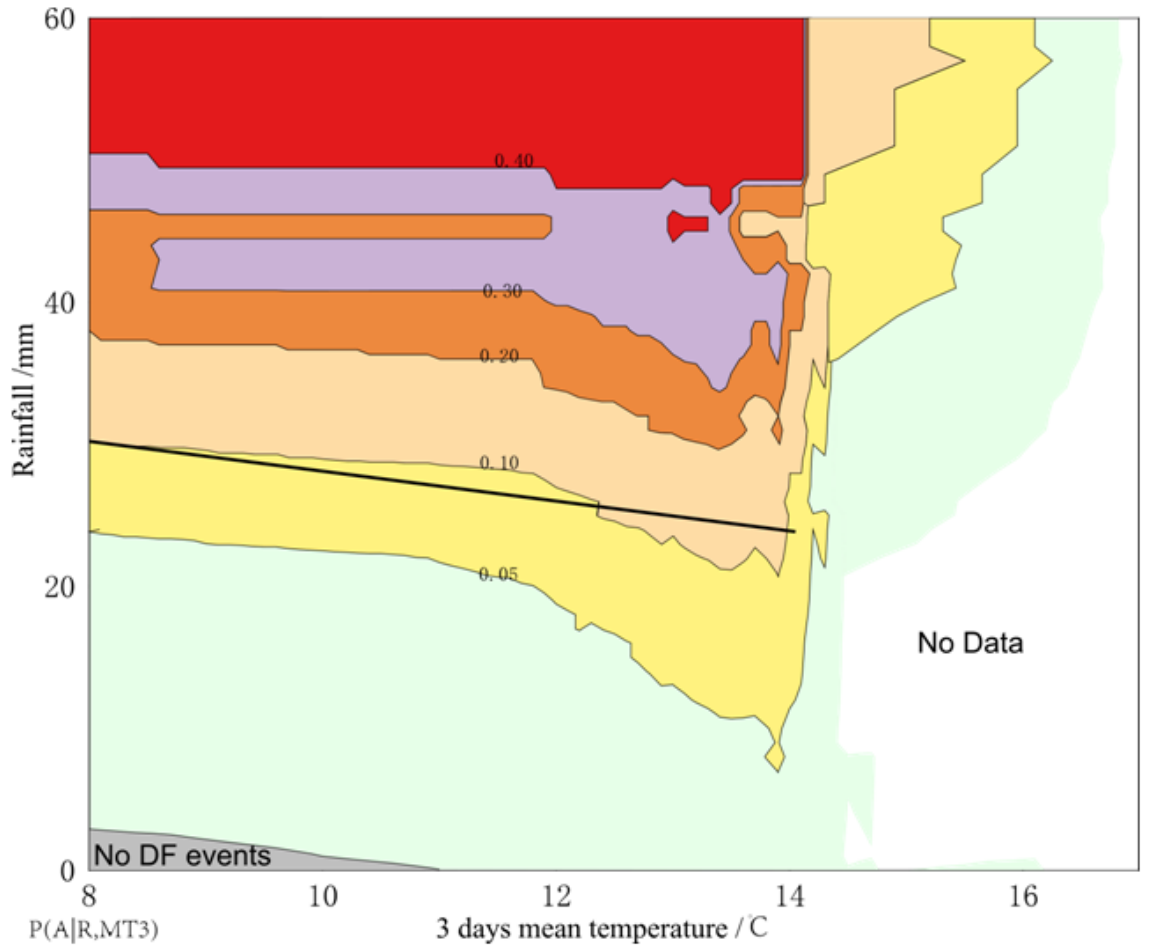


Figure 6

Lines of equal debris flows conditional probability in the rainfall-3 days mean temperature (note that isolines are not equally spaced). Black lines represent different rainfall thresholds forthe probability of acceptable debris flow conditions. The striped area shows meteorological conditions that never occurred. 